\title{
IDENTIFICAÇÃO DE ESPAÇOS PARA AS PRÁTICAS AMBIENTAIS NA CIDADE DO NATAL/RN: UMA ANÁLISE DE REFERENCIAIS VEICULADOS NA WEB
}

\author{
R. L. Lima ${ }^{1}$, W. I. T. S. Barros ${ }^{1}$, M. G. L. Silva ${ }^{1}$, E. A. de Almeida ${ }^{1}$ \\ ${ }^{1}$ Programa de Pós-Graduação em Ensino de Ciência e Matemática/UFRN \\ rlucas07@hotmail.com - lekinhabarros@yahoo.com.br - marciaglsilva@yahoo.com.br - \\ elineiaraujo@yahoo.com.br
}

Artigo submetido em outubro/2011 e aceito em abril/2013

\section{RESUMO}

A educação ambiental com seu aspecto interdisciplinar apresenta potenciais muito significativos para contribuir com a conservação de áreas naturais e assim garantir a acessibilidade da população a espaços vivenciais passíveis de sensibilização frente à necessidade de se conservar a biodiversidade. Nesse sentido, o objetivo deste trabalho foi identificar pontos vivenciais significativos na temática ambiental frente aos problemas que a população está constantemente exposta. Com grande probabilidade de obter êxito nas respostas aos desafios de trabalhar a educação ambiental voltada para o exercício da cidadania. Foram desenvolvidas pesquisas online utilizando palavraschave direcionadas para buscar as informações sobre a educação ambiental associando-as com informações direcionadas para valorização da diversidade biológica presente nos espaços educativos para prática na cidade de Natal/RN.

PALAVRAS-CHAVE: Aula de campo, espaços florestais, fauna e flora, sensibilização.

\section{IDENTIFICATION OF SPACES FOR ENVIRONMENTAL PRACTICES IN NATAL CITY: AN ANALYSIS OF REFERENCE AIRED ON WEB}

\section{ABSTRACT}

Environmental education with its interdisciplinary aspect has very significant potential to contribute to the conservation of natural areas and thereby ensure the accessibility of population to areas subject to experiential awareness towards the need to conserve biodiversity. Thus, the objective of this study was to identify significant points in experiential environmental issues facing the problems that people are constantly exposed. Most likely to succeed in the responses to the challenges of working environmental education focused on the exercise of citizenship, online surveys were developed using targeted keywords to search for information about environmental education associating them with information targeted for recovery biodiversity present in the spheres of education for practice in Natal / RN.

KEY-WORDS: Field class, forest spaces, fauna and flora, sensitization. 


\section{IDENTIFICAÇÃO DE ESPAÇOS PARA AS PRÁTICAS AMBIENTAIS NA CIDADE DO NATAL/RN: UMA ANÁLISE DE REFERENCIAIS VEICULADOS NA WEB}

\section{INTRODUÇÃO}

De acordo com Dias (1992), há cinco milhões de anos, os primeiros seres humanos que habitaram o Planeta enfrentaram inúmeras dificuldades e desafios, pois "a natureza era mais poderosa que os homens", ou seja, o homem não tinha domínio sobre a natureza, mas era domado por ela. Todos precisavam saber quais frutos serviam para comer, onde encontrar água durante a seca, como evitar animais selvagens, que plantas serviam para fazer um bom remédio, ou se poderiam ser utilizadas como materiais de construção.

Naquele momento o conhecimento ambiental era também necessário para a proteção contra ataques da natureza e para o melhor aproveitamento de suas riquezas. Esse conhecimento era passado de geração em geração, muitas vezes, acrescido de novas descobertas e a interação entre os homens e o ambiente ultrapassou a questão da simples sobrevivência.

Ainda considerando as informações obtidas em Dias (1992), com a urbanização e "evolução" da civilização, a percepção do ambiente mudou drasticamente e a natureza passou a ser entendida como "algo separado e inferior à sociedade humana", ocupando uma posição de subserviência. No decorrer do século XX, para atender as necessidades humanas foi desenhada uma equação desbalanceada: retirar, consumir e descartar. Nesse sentido, a humanidade como um todo, não tem cuidado bem do planeta, nem dos seres que nele vivem.

Como destaca Effeting (2007), foi a partir da Revolução Industrial que a natureza passou a ser administrada como um "supermercado gratuito, com reposição infinita de estoque", gerando, entre outros, o esgotamento de recursos naturais, a destruição de ecossistemas e a perda da biodiversidade, afetando, assim, os mecanismos que sustentam a vida na Terra e evidenciando o modelo de desenvolvimento "insustentável" por trás desta realidade.

A maior parte da população vive em centros urbanos e está habituada a água limpa que sais pela torneira e a suja pelo ralo, o lixo produzido diariamente é levado da frente das casas sem as pessoas terem a mínima preocupação de saber qual o seu destino. Ou seja, a grande maioria da população não consegue perceber a estreita correlação do meio ambiente, com o seu cotidiano (DONELA, 1997).

Ao contrário de outros seres vivos que, para sobreviverem, estabelecem naturalmente o limite de seu crescimento e, consequentemente, o equilíbrio com outros seres e o ecossistema, a espécie humana não consegue estabelecer o seu limite de crescimento, assim como tem dificuldade para relacionar-se com outras espécies e com o planeta (DONELA, 1997). Isto contribui muito para criar uma fronteira entre o conhecimento e a ignorância humana sobre sua própria casa, o Planeta Terra.

Fica evidente a importância de sensibilizar os humanos para que ajam de modo responsável e com consciência, conservando o ambiente saudável no presente e para o futuro; 
para que saibam exigir e respeitar os direitos próprios e os de toda a comunidade, tanto local como internacional; e se modifiquem tanto interiormente, como pessoas, quanto nas suas relações com o ambiente.

Uma educação transformadora envolve não só uma visão ampla de mundo, como também a clareza da finalidade do ato educativo, uma posição política e competência técnica para programar projetos a partir do aporte teórico e formador de profissional competente (PHILIPPI; PELICIONI, 2005).

Na perspectiva de abranger o sentido da Educação Ambiental no Rio Grande do Norte, para um pensar mais direcionado para os seres vivos em geral, os objetivos deste trabalho foram: a) averiguar, por meio de levantamento bibliográfico, informações sobre a temática educação ambiental, incluindo pontos significativos que possam valorizar o significado da biodiversidade nas práticas ambientais no $\mathrm{RN}$; b) identificar espaços estratégicos para as práticas de Educação Ambiental envolvendo o contato com os animais e as plantas; c) Propor sugestões de atividades que levem à sensibilização acerca do meio ambiente, essencialmente aquele mais próximo da realidade de cada população-alvo.

\section{METODOLOGIA}

Na perspectiva de vivenciar a educação ambiental nas suas relações com a biodiversidade foram consideradas as ênfases dadas por Pegoraro e Sorrentino (1998) sobre a conservação da fauna e flora por meio da Educação Ambiental no sentido de promover a sustentabilidade nas ações aplicadas. Leituras em Carvalho (1991-2004); Kraemer (2004); Layrargues (1998); Leff $(2000,2001)$ também foram desenvolvidas.

Como forma de esclarecimento teórico sobre a prática da Educação Ambiental é importante que o educador esteja atualizado dentro de um referencial teórico compatível com a cultura local onde está inserido (GALIAZZI; FREITAS, 2005; SATO; CARVALHO, 2005). Apropriar-se do conteúdo informativo sobre a temática desenvolvida na região de onde se pretende estudar também se torna necessário.

Para um melhor aproveitamento das atividades de campo com enfoque na biodiversidade é necessário obter informações teóricas e práticas para os esclarecimentos conceituais sobre o espaço e a diversidade biológica que se pretende observar. Buscar desenvolver vínculos intelectuais com o objeto de trabalho, é o primeiro caminho a fazer no sentido de cumprir o objetivo mais fluente na busca de soluções para os problemas.

Leituras em artigos construídos dentro da realidade regional possibilitam ter um forte aliado no enfretamento aos problemas locais. Nesse aspecto, fazer levantamentos bibliográficos para obtenção de conhecimentos específicos sobre locais estratégicos para se praticar o exercício de educação constitui um ponto também importante para tornar as experiências mais interessantes e motivadoras. 
De acordo com a obra de Machado (2004), um dos melhores mecanismos de busca conceitual na internet, acerca de assuntos sobre regiões geográficas mais específicas é o site de busca Yahoo (www.yahoo.com que é o mais antigo dos diretórios da Web ${ }^{1}$ ), WEB - World Wide $W e b$, ele é o mais recomendado para tais buscas. Há também o site www.google.com, para mais detalhes sobre as buscas e confirmação de referências acerca de conteúdos locais. Neste trabalho, uma averiguação nas 10 primeiras páginas dos dois sites, utilizando algumas fraseschave, já foi ideal para ser feito levantamento de informação básica.

Considerando que um dos aspetos da pesquisa foi obter informações acerca dos espaços locais abordando o tema biodiversidade contextualizado com a educação ambiental, enfatizaram-se, para a amostra de análise, os conteúdos divulgados em sites de busca de fácil acesso na mídia local. Essa pesquisa faz com que o trabalho se torne passível de ser desenvolvido, também, por estudantes de níveis mais basais. Nesse material bibliográfico de análise foram incluídos tanto artigos de jornais e divulgações gerais em sites diversos, como artigos científicos desenvolvidos sobre os espaços de práticas de educação ambiental. Para a seleção da amostra foram seguidos princípios abordados na análise de conteúdo sistematizada por Bardin (2010), no sentido de buscar comparação nas mensagens divulgadas e explicitar algumas categorias relevantes relacionadas com a valorização da biodiversidade local. Porém, para aprofundamento conceitual das informações obtidas, foram selecionados artigos de expressiva qualificação junto aos meios de divulgação científica. Todos os arquivos foram salvos em PDF (Portable Document Format ou "Formato de Documento Portátil").

Sabendo-se que, embora não explicitamente destacado, o tema biodiversidade é subjacente em práticas ambientais diversas, ao buscar informações sobre educação ambiental, no geral, recaindo sobre o contato com os organismos diversos. Então, buscas por frases-chave, tais como "educação ambiental e biodiversidade", "educação ambiental nas escolas Natal/RN"; "lazer recreativo e educação ambiental Natal/RN", "espaços urbanos e educação ambiental Natal/RN", "tipos de atividades ambientais em parques de Natal/RN", "educação ambiental em ambientes costeiros Natal/RN", "educação ambiental em matas Natal/RN", foram inseridas no site de busca Google. Para refinamento da amostra de análise, fez-se uma seleção amostral, privilegiando os pontos mais conhecidos da cidade. Uma busca rápida que indicasse um perfil mais aproximado acerca do lugar foi avaliar as informações contidas no site www.wikpedia.com. As prioridades foram voltadas para as atividades de campo desenvolvidas, por meio das mais variadas formas possíveis, a começar por discussões em classe de textos e reportagens sobre Meio Ambiente, trabalhos socioambientais em grupo, aulas audiovisuais, debates e oportunidades de palestrantes especializados em meio ambiente na instituição, temáticas ecologicamente corretas para as datas comemorativas do calendário acadêmico, simulação de um tribunal ecológico para debate das causas e consequências, malefícios e benefícios do desenvolvimento e conservação ambiental. A busca de locais para a sensibilização ambiental que

\footnotetext{
${ }^{1}$ Nome pelo qual a rede mundial de computadores internet se tornou conhecida a partir de 1991, quando se popularizou devido à criação de uma interface gráfica que facilitou o acesso e estendeu seu alcance ao público em geral.
} 
despertem reações e sentimentos de preservação é passível de serem exploradas em diversas fontes e por isso têm espaços importantes na discussão com os discentes.

\section{RESULTADOS E DISCUSSÃO}

Após consulta ao site de busca www.yahoo.com, com devidas complementações no site www.google.com, utilizando as frases-chave indicadas, tiveram como ocorrências marcantes algumas informações sobre os pontos estratégicos, inserindo em seus contextos o tema da educação e potencializando a temática da Educação Ambiental no Município do Natal direcionada para a biodiversidade.

Áreas com espaços florestais disponíveis na cidade do Natal, tais como: a) Parque das Dunas, localizado na Av. Alexandrino de Alencar - Tirol, relacionado ao emblema verde da cidade exaltando as trilhas; b) Rio Potengi, através do projeto Barco-escola "Chama-Maré"; c) Cidade da Criança, situada na Av. Rodrigues Alves - Tirol; d) Parque da Cidade, localizado no prolongamento da Av. Prudente de Morais; e) Praias de Ponta Negra e Praia da Redinha. Essas áreas constituem espaços significativos para as diversas práticas de Educação Ambiental na Cidade do Natal/RN envolvendo o contexto da biodiversidade.

Trabalhos enfocando a temática sobre a Educação Ambiental no Parque das Dunas foram, principalmente, àqueles representados por artigos enfocando o Projeto Nativas, no Campus/UFRN. Artigos e notas em jornais de circulação no município abordando sobre as trilhas ecológicas e sua importância para Educação Ambiental e preservação da Mata Atlântica no Estado. Além disso, os destaques de eventos governamentais vinculados ao emblema ambiental da cidade, foram encontrados também em manchetes turísticas sobre o Parque das Dunas exaltando, assim, as belezas naturais da cidade e seu ar puro.

São poucos os trabalhos sobre Educação Ambiental em periódicos, artigos ou notas em revistas especializadas. Porém, vale destacar o trabalho de Coelho, Araújo-de-Almeida e Lima (2007) destacam a possibilidade de boas práticas de Educação Ambiental em ambientes naturais presentes nas áreas urbanas. Também, como destacaram Araújo-de-Almeida et al. (2010) é possível contribuir com a divulgação sobre temas da biodiversidade envolvendo atividades de campo desenvolvidas na sala de aula e assim tornar mais acessível as informações produzidas.

O Rio Potengi foi visto como um potencial para a prática da Educação Ambiental por intermédio do Barco-escola "Chama-Maré". Foi encontrada muita divulgação de informações relacionadas ao meio ambiente, nas esferas governamentais em sites das Secretarias do Governo do Estado e Município, como o do Instituto de Desenvolvimento Sustentável e Meio Ambiente do RN (IDEMA); da Secretaria de Estado da Administração e dos Recursos Humanos do RN (SEARH); da Fundação de Apoio à Pesquisa do Estado do RN (FAPERN); Secretaria Municipal de Meio Ambiente e Urbanismo (SEMURB) e do Instituto Federal de Educação, Ciência e Tecnologia do Rio Grande do Norte (IFRN), sobre o projeto e sua aceitação pela comunidade e importância para preservação do Rio Potengi. 
A Cidade da Criança no passado foi um grande centro de lazer e interação com o verde e de educação ambiental para crianças do município de Natal. Mas, encontra-se abandonada pelo poder público e sem atividades significantes para população há muito tempo. Não há registro algum de artigo proveniente de pesquisa científica. Citam-se apenas alguns projetos de restauração por parte dos órgãos públicos que poderão gerar informações no futuro.

Algumas praias urbanas também podem ser buscadas para ações de sensibilização e através do projeto desenvolvido pelo IFRN a respeito de "Análises de águas, efluentes e estudos costeiros", bem como suas produções acadêmicas na área através de monografias e artigos científicos com um enfoque mais técnico para o meio ambiente.

O recém-inaugurado Parque da Cidade Dom Nivaldo Monte já desperta atenção nas questões sobre Educação Ambiental. Embora não tenha sido registrado nenhum artigo proveniente de pesquisa científica, citam-se tal como para Cidade da Criança, alguns projetos como trilhas ecológicas, manejo da fauna e da flora, educação hídrica entre outros que poderão gerar informações no futuro.

Quanto aos espaços destinados às práticas de Educação Ambiental, a Cidade do Natal está bem assistida com áreas verdes de todos os tamanhos e formas para o exercício da educação ambiental tanto para o ensino em turmas do Ensino Fundamental e Médio quanto para o Ensino Superior, além de entretenimentos para diversas faixas etárias. Porém, os trabalhos realizados nestas áreas não são divulgados em nível de um trabalho científico publicado e indexado em sites de busca, mas são bastante divulgados na mídia local, seja imprensa, rádio/TV, ou pela internet, neste caso, principalmente, nos endereços eletrônicos governamentais.

Os trabalhos e projetos desenvolvidos nas escolas são bastante numerosos nas diversas zonas da cidade, porém não são divulgados ou lapidados para se tornarem uma informação contida em periódicos indexados, eles ficam na esfera local escola-comunidade, seja na instituição privada ou pública. Nesta última, os governos desenvolvem várias atividades sobre Educação Ambiental sendo o carro chefe na produção de informações e vinculação na comunidade desta prática saudável de convívio com a natureza. As escolas possuem anualmente uma agenda que perdura por um dia ou uma semana de eventos voltados para Educação Ambiental e passar a acionar essa temática no cotidiano escolar, da comunidade e documentar essas ações para que se possa ter um referencial do que está acontecendo significativamente sobre Educação Ambiental nas escolas do município seja do governo ou da prefeitura é um passo importante para se ter um material de referencial local e assim incentivar as práticas ambientais mais constantemente.

As Organizações não Governamentais (ONG), como a Associação Potiguar Amigos da Natureza (ASPOAN), ONG Oceânica, entre outras que também realizam trabalhos voltados para a Educação Ambiental junto às escolas. Mas, não foram encontrados trabalhos científicos destas instituições com educação ambiental nas escolas, e sim sobre os projetos que elas desenvolvem pontualmente. Acerca da ONG Oceânica podem ser destacadas algumas ações ambientais, como a atuação no Projeto "Dia Internacional de Limpeza de Praia", em praias do Rio Grande do Norte, 
em parceria com a ONG Australiana Clean-up the world e a Universidade Federal do Rio Grande do Norte (UFRN). Tudo isso soma material educativo a ser colocado na sala de aula.

Despertar o aluno para os problemas ambientais que surgirão se a população não se conscientizar de que sua sustentabilidade no planeta está ligada à conservação dele, vem sendo documentado frequentemente no contexto da temática ambiental (ver BRASIL, 1988, 1997, 1998; PRONEA, 2003).

O aspecto educativo, segundo Carvalho (2001) deve ser firmado no modo diferente de agir na sua casa, na escola, no seu ambiente de trabalho, ou na sociedade como um todo, para que ele entenda e participe e ajude a disseminar uma ideia tão maravilhosa que só trará bons frutos para nossa convivência na sociedade. Neste caso, o espaço escolar deve contemplar características que possibilitem o desenvolvimento de aprendizagens que favoreçam a atividade livre e criativa da criança, exigindo também uma participação coletiva e cooperativa, num processo que envolve desde a tomada de decisões entre os estudantes até a implementação do que se propõe nas decisões (NUTTALL, 1999).

\section{CONSIDERAÇÕES FINAIS}

A prática da Educação Ambiental é em si é um desafio, pois exige um reaprendizado e ruptura com a cultura e comportamento dos alunos e da comunidade. Nesta construção são necessárias novas atitudes, com todas as possibilidades materiais para que isso aconteça. Sensibilizar os estudantes para a necessidade de autossustentar, preservar, manter, zelar, viver em harmonia com o meio ambiente, incluindo nesse contexto, toda a biodiversidade, inclusive os humanos como um ser animal é de extrema importância no contexto da conservação do Planeta Terra. Também, estimular nos alunos a capacidade de fazer com que eles compartilhem o aprendizado com seus familiares e com toda a comunidade, são sugestões coerentes a serem feitas na inserção da temática da Educação Ambiental como eixo transversal, fortalecendo a compreensão de que os seres estão todos interligados no ambiente e todos têm direito à vida. As excussões de alunos para tais locais promovem a sensibilização frente à ação coletiva, direcionando-os para o enfrentamento com os conflitos socioambientais. Além disso, se proporciona um momento de reflexão acerca da importância dos espaços florestais de uso coletivo que ainda podem ser encontrados nos locais urbanos.

\section{REFERÊNCIAS}

1. ARAÚJO-DE-ALMEIDA, E.; BARROS, W. I. T.; GOIS, J. S. et al. Dinamicidade no ensino: exercitando a construção e a divulgação de conhecimentos sobre o percurso da sala de aula. Revista da SBEnBIO. , v.3, p.3230 - 3237, 2010. Disponível em: <http://www.sigaa.ufrn.br/sigaa/verProducao?idProducao=586934\&key=c28be505c1a91 b762accaae84169d05c>. Acesso em: 29 set. 2011. 
2. BARDIN, L. Análise de conteúdo. Lisboa: Edições 70, 2010.

3. BRASIL. Constituição da República Federativa do Brasil: promulgada em 5 de outubro de 1988. Organização do texto: Juarez de Oliveira. 4. ed. São Paulo: Saraiva (Série Legislação Brasileira). 168 p. 1990.

4. BRASIL. Parâmetros Curriculares Nacionais: introdução aos parâmetros curriculares nacionais. Secretaria de Educação Fundamental. Brasília: MEC/SEF, 1997. Disponível em: < portal.mec.gov.br/seb/arquivos/pdf/ttransversais.pdf>. Acesso em: 23 set. 2011.

5. BRASIL. Lei Federal, n. 6.938, de 31 de agosto de 1981. 2007. Disponível em: < http://www.ambitojuridico.com.br/site/index.php?n_link=revista_artigos_leitura\&artigo_id=750 0>. Acesso em: 23 set. 2011.

6. CARVALHO, I. Ecologia, desenvolvimento e sociedade civil. Revista de Administração Pública. Rio de Janeiro, 25(4): 2-45, 1991 . Disponível em: <http://bases.bireme.br/cgibin/wxislind.exe/iah/online/?IsisScript=iah/iah.xis\&nextAction=Ink\&base=LILACS\&exprSearch=11 1129\&indexSearch=ID\&lang=p>. Acesso em 23 set. 2011.

7. CARVALHO, I. C. M. Educação ambiental: a formação do sujeito ecológico. São Paulo: Cortez, 2004.

8. GALIAZZI, M. C.; FREITAS, J. V. (org.). Metodologias emergentes de pesquisa em educação ambiental. ljuí: Edljuí, 2005.

9. COELHO, M. S.; ARAUJO-DE-ALMEIDA, E.; SANTOS. R. L. Fauna inquilina de bromélias: proposta de instrumental didático integrando a Zoologia e a Educação Ambiental In: ARAÚJO-DE-ALMEIDA (org.). Ensino de Zoologia: ensaios interdisciplinares. João Pessoa: EdUFPB, 2009, p. 165-189

10. DIAS, G. F. Educação Ambiental: princípios e práticas. São Paulo, Gaia, 1992.

11. EFFTING, T. R. Educação Ambiental nas Escolas Públicas: realidade e desafios. Monografia (Pós Graduação em "Latu Sensu" Planejamento Para o Desenvolvimento Sustentável) - Centro de Ciências Agrárias, Universidade Estadual do Oeste. 2007. Disponível em: $<$ terrabrasilis.org.br\%2Fecotecadigital\%2Fpdf\%2Fautoresind\%2FEducacaoAmbientalNasEscolasP ublicasRealidadeEDesafios.pdf>. Acesso em: 12 maio. 2011.

12. FERREIRA, D. R. D. Implantação da educação ambiental na escola: reflexões sobre uma experiência. Fundação Municipal de Educação de Niterói, RJ. Disponível em: $<w w w$.diariodoprofessor.com/.../implantacao-da-educacao-ambiental--na-escola: reflexões+sobre+uma+experiência>. Acesso em: 27 ago. 2011.

13. GUIMARÃES, M. A dimensão ambiental na educação. Papirus Editora, 1995.

14. HOUAISS, A.; VILLAR, M. de S.; FRANCO, F. M. de M. Dicionário eletrônico Houaiss da língua portuguesa. Rio de Janeiro: Objetiva. 1 CD-ROM, versão, 3.0, 2009.

15. KRAEMER, M. E. P. Gestão ambiental: um enfoque no desenvolvimento sustentável. Curitiba, 2004.

16. LAYRARGUES, P. P. Educação para a gestão ambiental: a cidadania no enfrentamento político dos conflitos socioambientais. In: LOUREIRO, C. F. B., LAYRARGUES, P. P.; CASTRO, R. S. Sociedade e meio ambiente: a educação ambiental em debate. 1998.

17. LEFF, E. Ecologia, capital e cultura: racionalidade ambiental, democracia participativa e desenvolvimento sustentável. Blumenau: Ed. da Furb, 2000.

18. E. Saber ambiental: sustentabilidade, racionalidade, complexidade, poder. Petrópolis: Vozes, 2001. 
19. MACHADO, J. "Como Pesquisar na Internet - Métodos, Técnicas e Procedimentos Gerais". 2004. Disponível em: <http://www.forum-global.de/curso/textos/pesquisar_na_internet.htm>. Acesso em: 10 nov. 2008.

20. MEADOWS, D. Conceitos para se fazer educação ambiental. Tradução e adaptação de Maria Julieta A. C. Penteado. Ed. Coordenadoria de Educação Ambiental da Secretaria de Meio Ambiente do Estado de São Paulo - 2' ed. revisada, sob coordenação de Suzana Pádua e publicada por IPÊ (Instituto de Pesquisas Ecológicas), MEC, SMA, UNESCO e UNICEF, 115 p. 1997.

21. NUTTALL, C. Agrofloresta para crianças: uma sala de aula ao ar livre. Bahia: Instituto de Permacultura da Bahia, 1999.

22. PEGORARO, J. L.; SORRENTINO, M. Programas educativos com fauna e flora (Expressões da Biodiversidade) e a Educação Ambiental. Scientia Florestalis. $n^{\circ}$ 54. p. 131-142. dez. 1998. Disponível em: <www.ipef.br/publicacoes/scientia/nr54/cap11.pdf>. Acesso em: 20 ago. 2011.

23. PHILIPPI JR., A. PELICIONI, M. C. F. Educação Ambiental e Sustentabilidade. Editora Manole, 2005.

24. PRONEA. Programa Nacional de Educação Ambiental. Secretaria do Meio Ambiente. 2003. Disponível em: <portal.mec.gov.br/secad/arquivos/.../educacaoambiental/pronea3.pdf>. Acesso em: 20 ago. 2011.

25. SATO, M.; CARVALHO, I. Educação Ambiental: pesquisa e desafios. São Paulo: ARTMED, 2005.

26. TAGLIEBER, J. E.; GUERRA, A. F. S. (orgs.) Pesquisa em Educação Ambiental: pensamentos e reflexões de pesquisadores em Educação Ambiental. Pelotas: Editora Universitária/ UFPel, 2004 